\title{
Design of Power Supply Unit for Passive UHF RFID Tag
}

\author{
Alexander S. Sinyukin \\ MSc of Southern Federal University, Russia \\ 44, Nekrasovsky lane, Taganrog, 347928, Russia
}

*Corresponding Author: Alexander S. Sinyukin, MSc of Southern Federal University, Russia

44, Nekrasovsky lane, Taganrog, 347928, Russia

\begin{abstract}
The survey and development of power supply unit for passive RFID tag functioning on ultra-high frequency are presented in this paper. RFID (radio-frequency identification) is a technique of objects identification in which data, stored in radiofrequency transponders or tags, is read and wrote by means of radio signals. One of the most important parts of RFID tag providing the energy for proper operation of tag is power supply module. Power supply unit can include such cells for harvesting and provision of energy as voltage rectifiers and multipliers, voltage regulators, bias schemes and others. This work considers design features of the rectifier with voltage multiplying which is capable to provide rectified voltage of $1.2 \mathrm{~V}$ while input radiofrequency voltage amplitude is less than $0.7 \mathrm{~V}$. The circuit functions at $2.45 \mathrm{GHz}$ frequency and is designed for implementation using $90 \mathrm{~nm}$ CMOS technology. Comprehensive simulation of the rectifier operation with variations of determining parameters was conducted. Besides, the voltage reference for voltage regulator was also developed and simulated.
\end{abstract}

Keywords: UHF RFID tag, power supply unit, voltage rectifer, multistage circuit, CMOS technology

\section{INTRODUCTION}

Radio-frequency identification devices are used primarily for automatic identification and tracking of different objects in logistics and production chains. Moreover they have found practical use in toll collection, access control systems and cashless payment operations. Generally RFID system consists of transponder, reader and server with databases to which the reader addresses when it requests and process received information. Data and energy are usually transferred between tag and reader through microwave radiation (backscattering) or inductive coupling [1]. Radio-frequency identification tags usually include analog high-frequency cascades, modulation and demodulation units, digital processing schemes and, in some cases, memory elements, Figure 1 [2]. In addition auxiliary schemes of different purposes, like clock oscillator or mode selector, can be incorporated in a tag. In process of RFID tags design the problems related with matching between microchip and tag's antenna should be resolved in order to obtain acceptable performance and required reading distance.

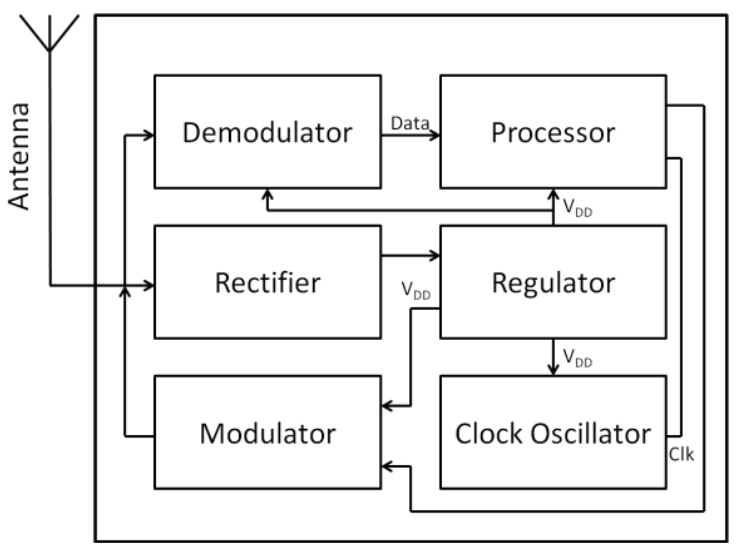

Figure1. Block diagram of passive UHF RFID tag [2] 
Functional units responsible for conversion the energy of HF signal to DC voltage play a key role in operation of the transponder. Due to usage of various modifications of voltage rectifiers, regulators and limiters, microcircuit of the passive tag can have enough power both for correct functioning and for transmission the backscattering signal. In this paper we described the design of multistage halfwave voltage rectifier circuit intended for operation in a passive UHF RFID tag as well as the structure of voltage reference which is able to produce the input voltage for voltage regulator.

\section{Proposed Power Supply Module for Passive Rfid Tag}

\subsection{TECHNOLOGICAL ASPECTS OF THE DESIGN}

Design of power supply of passive RFID tag has been carried out for assumed implementation in CMOS technological process with $90 \mathrm{~nm}$ design rules and threshold voltage of NMOS $V_{\text {th }}=0.28 \mathrm{~V}$. Employment of strained silicon to speed up carrier mobility in the channel of transistor became one of the most important innovation related with $90 \mathrm{~nm}$ technology. Horizontal strain can be created by the silicon nitride capping layer [3] or mixed semiconductor silicon-germanium ( $\mathrm{SiGe}$ ) [4]. The strain increases the distance between atoms under the gate. Since dispersal of atoms leads to advance of carrier mobility, saturation current increases by $10-25 \%$ [4].

During the design of power supply of passive RFID tag, transistors with low-leakage current have been used. These transistors are described by BSIM4 model. Besides, the type of high-speed transistor was reviewed. These types of MOS devices differ from each other mainly in values of threshold voltage ( $V_{\mathrm{th}}=0.26 \mathrm{~V}$ for high-speed transistor) and channel-length offset parameter LINT. LINT is equal to $0.015 \mu \mathrm{m}$ for low-leakage transistor and $0.019 \mu \mathrm{m}$ for high-speed one. High-speed MOS is characterized by higher values of forward current $I_{\mathrm{ds}}(740 \mu \mathrm{A}$ at a voltage $1 \mathrm{~V}$ while for low-leakage NMOS transistor $I_{\mathrm{ds}}=630 \mu \mathrm{A}$ at similar voltage). Hence resulting voltage at the output of rectifying circuit slightly increases.

However reverse currents also increase approximately one and a half orders of magnitude in such transistor. In the case of low-leakage transistor reverse current is about $30 \mathrm{nA}$ (at voltages $V_{\mathrm{bs}}=0$ and $V_{\mathrm{gs}}=0$ ) and in the case of high-speed transistor - about $300 \mathrm{nA}$. Since PCE (power conversion efficiency) of rectifying circuit decreases when leakage currents grows [5] and this efficiency is not high enough in charge pump schemes compared to bridge rectifiers, it is necessary to maintain reverse current at the lowest possible level. And use of low-leakage MOS transistor facilitate to this.

\subsection{Design of Power Supply Module}

Voltage rectifier circuit plays a major role in powering the units of radiofrequency tag by DC voltage. So far as bridge rectifier circuits can show insufficient values of supply voltage at ultra-high frequency [6], half-wave rectifier with voltage multiplying also known as Dickson's pump circuit was taken as a basis [7]. The diodes had been used in traditional circuit for conversion alternating current to direct current since the current flows in one direction in these devices. However voltage drop on silicon diodes is usually $0.6-0.7 \mathrm{~V}$, therefore either voltage at circuit input should be high enough to attain satisfactory results or rectifying voltage will be small. Currently diode-connected MOS transistors are often used in rectifying circuits instead diodes. To form the diode-connected transistor its drain is coupled with its gate. Since in this instance turn-on voltage of transistor is approximately equal to its threshold voltage $\left(V_{\text {th }}\right)[8,9]$, this parameter should be reduced to a minimum. Also known cases of using Schottky-barrier diodes as rectifying cells which can operate at even less turn-on voltages but fabrication these circuits requires additional technological operations like photolithography so manufacturing cost increases.

According to the analysis, designs of passive RFID tags are more often focused at frequency band 860 - $960 \mathrm{MHz}$ while for operation at frequency $2.45 \mathrm{GHz}$ designs of active tags are mostly presented. For this reason design of the rectifier circuit of passive tag functioning at $2.45 \mathrm{GHz}$ was in particular interest. Furthermore, this frequency has a number of advantages: absence of necessity for licensing, possibility of using inexpensive flexible antennas in transceivers, satisfactory reflection from metal surfaces, adoptable penetration through non-conducting mediums [1].

Capacitors are used in rectifier circuits for charge pumping and charge accumulation. As can be seen from Figure 2, couple of capacitors is usually included in the single stage of rectifier with voltage multiplying. Capacitor $\mathrm{C} 1$ is charging through diode D1 during a negative half-wave of sinusoidal 
signal with amplitude $V_{\mathrm{RF}}$. Diode voltage is equal to $V_{\mathrm{RF}}-V_{\mathrm{D}}$, where $V_{\mathrm{D}}$ - turn-on voltage of the diode. During subsequent positive half-wave capacitor $\mathrm{C} 2$ is charging through diode $\mathrm{D} 2$. The charge accumulated in capacitor $\mathrm{C} 1$ is transferred to this capacitor too. So output voltage can be estimated in the following way [8]:

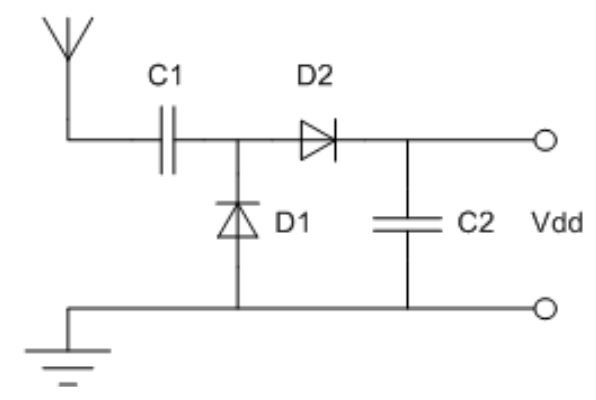

Figure2. Voltage doubler circuit [8]

$V_{D D}=V_{R F}+\left(V_{R F}-V_{D}\right)-V_{D}=2\left(V_{R F}-V_{D}\right)$.

Diode-connected MOS transistors are employed in proposed design instead of diodes but functioning principle remains the same. In the limit, when voltage $V_{\mathrm{D}}$ can be neglected, the circuit doubles voltage thereby it was so termed. With increase the number of stages at small voltage drops the output voltage can be expressed as

$V_{D D}=2 N\left(\mathrm{~V}_{\mathrm{RF}}-V_{D}\right)$,

Where $N$ - number of stages in circuit.

Actually, the output voltage attains lower values because of different energy losses. It will not succeed to add stages indefinitely since the more stages in the circuit the more energy is lost at the rectifying cells resulting in diminishing return effect.

One can preliminarily estimate the values of the capacitances used in the circuit from the value of the time constant $t$. If this time required for capacitor discharge is long enough compared to highfrequency cycle time, supply voltage will be approximately permanent during this cycle. The time constant can be expressed as

$t=R C$,

Where $C$ - capacitance, $R$ - load resistance of the circuit.

In the proposed design the load resistance is substituted by equivalent resistance. This parameter can be estimated either by direct review of similar rectifier circuits $[10,11]$ in which load is $100-200 \mathrm{k} \Omega$ or by using expression for power consumed by the circuit:

$P=\frac{V^{2}}{R} \rightarrow R=\frac{V^{2}}{P}$

Where $V$ - supply voltage.

It is known from literature analysis $[8,10,12]$ that average power consumed by UHF tag is usually from several units to several tens $\mu \mathrm{W}$. Assuming $P$ is equal to $10 \mu \mathrm{W}$ and considering required supply voltage as $1.2 \mathrm{~V}$, total load resistance of the tag is obtained equal to $144 \mathrm{k} \Omega$. The obtained value $R$ is consistent with the values of load from analyzed developments, therefore, the load value is taken as $100-200 \mathrm{k} \Omega$ in the design of power supply unit. Considering that the duration of high-frequency cycle (period of oscillation) for signal at frequency $2.45 \mathrm{GHz}$ is $T=0.4 \mathrm{~ns}$ and time constant should be at least ten times more than period $(t>10 T)$ [8], from (4) the order of magnitude for capacitances in multiplier circuit is equal to $40 \mathrm{fF}$. During testing the various options of the designed circuit, capacitances have been selected with allowance for obtained estimated value.

To attain acceptable values of supply voltage in proposed design NMOS devices with enlarged channel width W have been used. It is known from literature analysis that ratio W/L for transistors in rectifier circuits varies from 8 [13] to 85 [12] and more. Large ratio W/L leads to both high saturation 
current and substantial reverse currents. Hence the output voltage increases but power efficiency decreases. So different options of ratio $\mathrm{W} / \mathrm{L}$ have been reviewed in the process of design and acceptable value 20 was chosen.

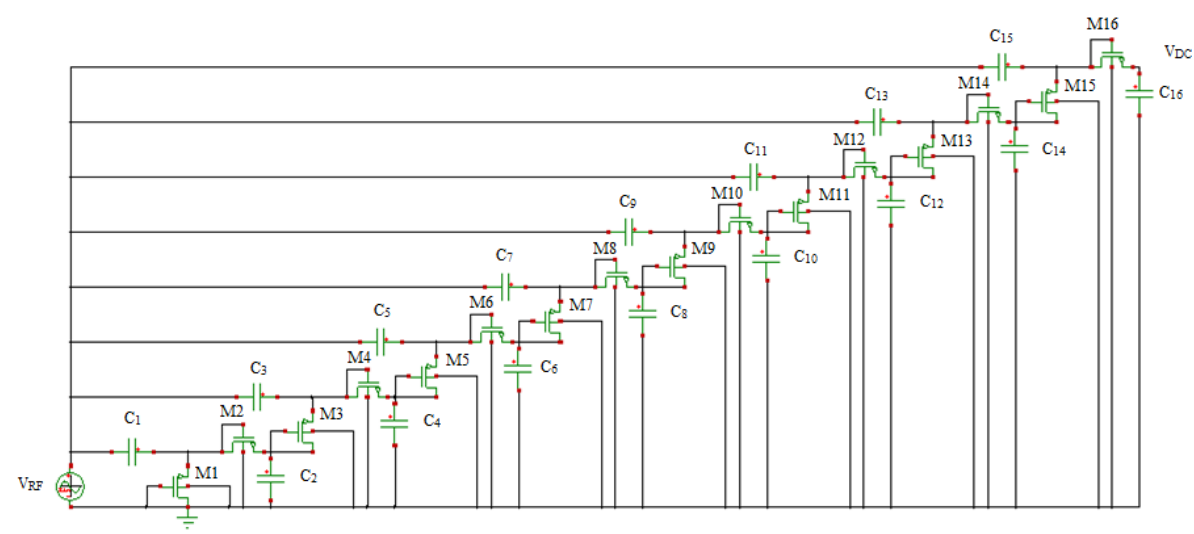

Figure3. Schematic circuit of proposed voltage rectifier

The schematic circuit of designed 8-stage rectifier with voltage multiplying is shown in Figure 3. DC voltage obtained at the circuit output reaches $1.22 \mathrm{~V}$ at input signal amplitude of $0.7 \mathrm{~V}$ and frequency of $2.45 \mathrm{GHz}$. Figure 4 shows the layout of 8-stage rectifier. The area of each odd capacitor $(C=200$ $\mathrm{fF})$ is equal to $960 \mu \mathrm{m}^{2}$, the area of each even capacitor $(C=150 \mathrm{fF})$ is $720 \mu \mathrm{m}^{2}$. One transistor with enlarged channel width $(\mathrm{W} / \mathrm{L}=20)$ occupies the area $1.44 \mu \mathrm{m}^{2}$. The total area of rectifier is 0.0153 $\mathrm{mm}^{2}$.

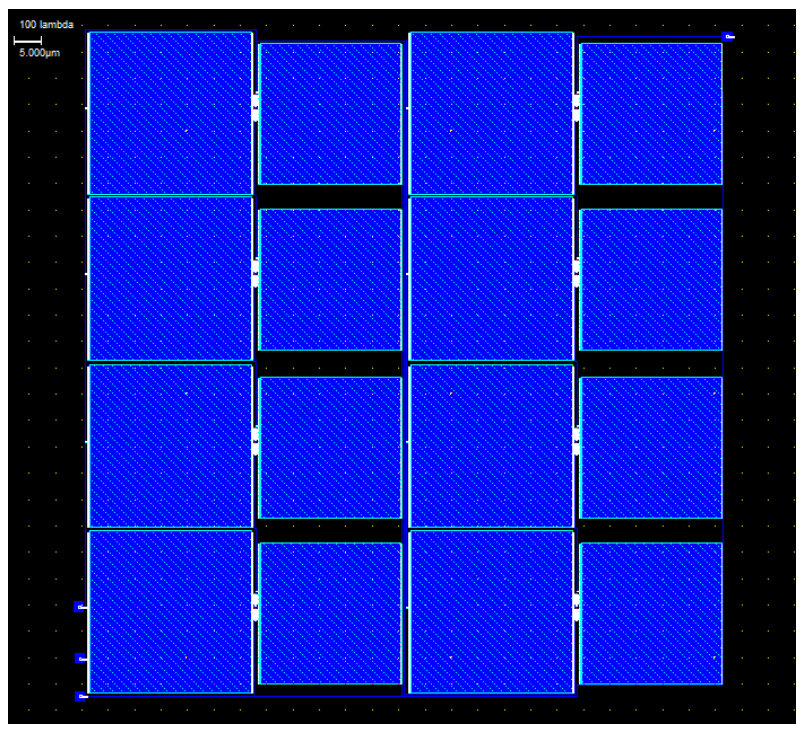

Figure4. The layout of rectifier with capacitors performed in 4 metal layers

Moreover during the design of power supply module for passive RFID tag, reference-voltage source for voltage regulator of the tag was developed. Structure of this functional unit was created based on constructions from [14]. In this instance reference-voltage consist of three NMOS and one PMOS diode-connected transistors as it shown in Figure 5.

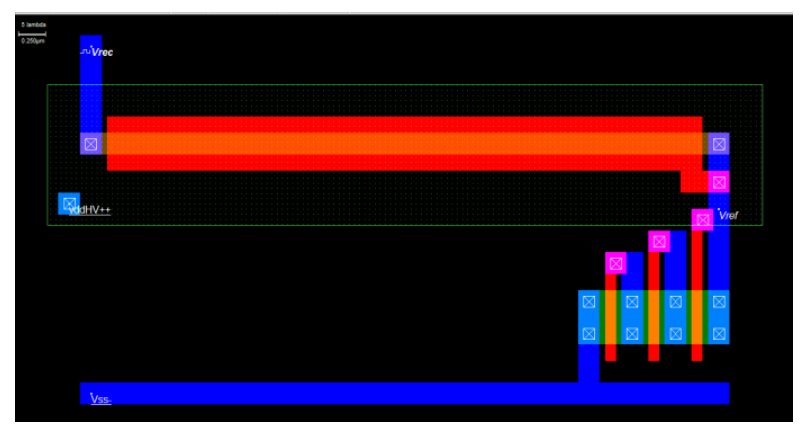

Figure5. The layout of reference-voltage source 


\section{SimUlation AND DiSCUSSION}

The simulation of rectifying structure has been carried out in circuit simulation environment T-Spice.

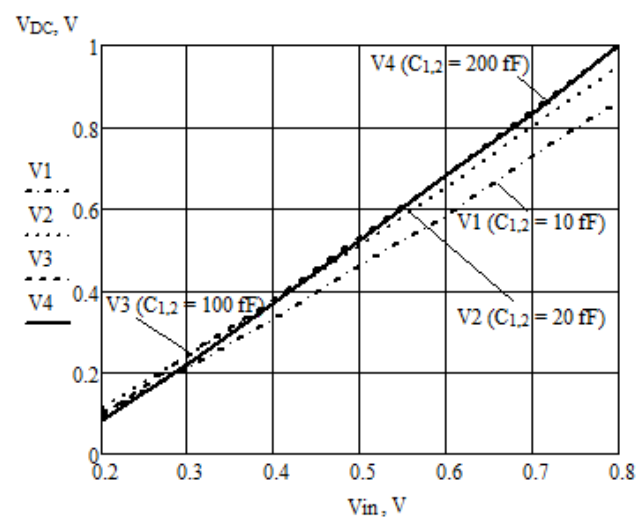

a

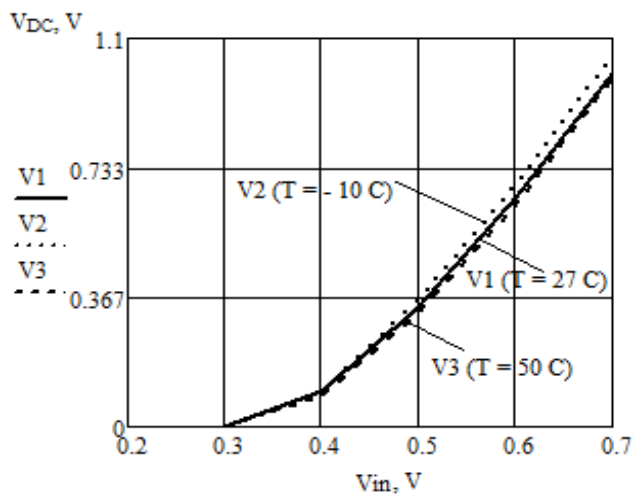

$\mathrm{c}$

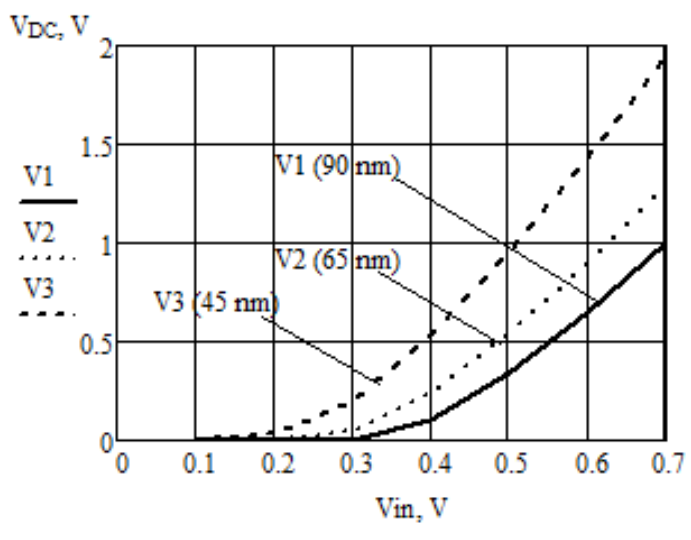

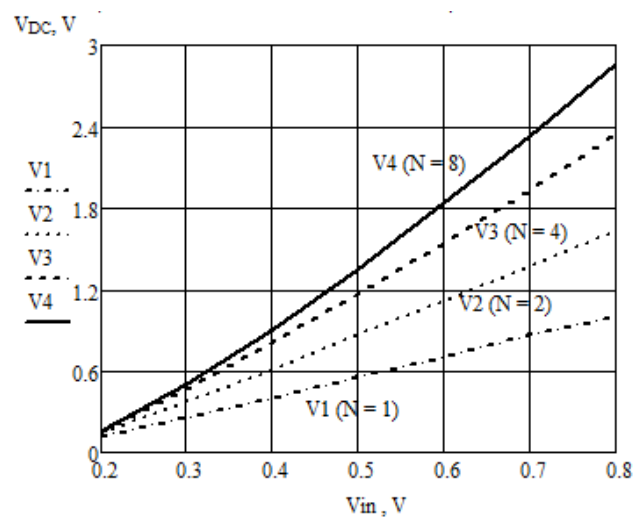

$\mathrm{b}$

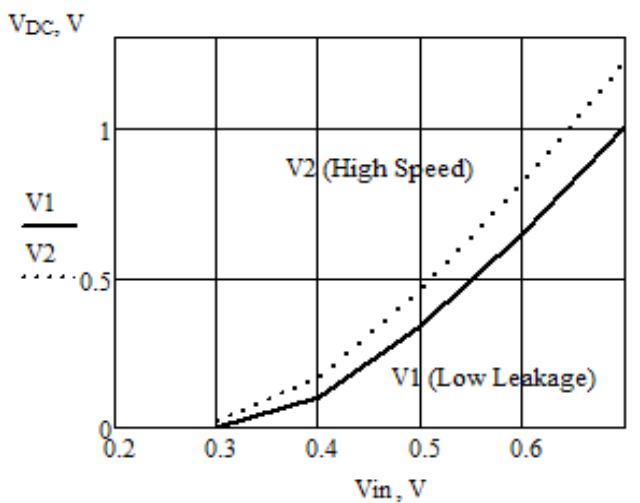

d

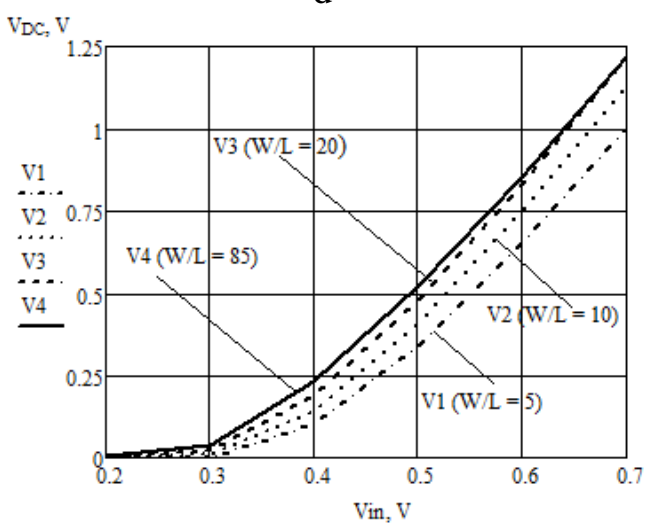

$\mathrm{f}$

Figure6. Simulation results of the voltage rectifier. $a$ - the influence of $C$ value on the output voltage of 1-stage circuit; $b$ - the output voltage as a function of number of rectifying stages; $c$ - the output voltage as a function of temperature; $d$-rectified voltage for different types of transistors, $e$ - the output voltage of rectifier under various design rules; $f$-alteration of ratio $W / L$ for increasing the output voltage

During the design of voltage rectifier providing supply voltage for passive radiofrequency tag, in the first place, trials to establish more precise values of capacitance were conducted. The plot of the output voltage versus the input voltage for some values of $C$ is shown in Figure 6a. As can be seen from the figure, when the total capacitance decreases to $20 \mathrm{fF}$ the output voltage level falls and in addition the rectification is not completely carried out. When the capacitance increases to $C_{1,2}=100$ $\mathrm{fF}$, the value of rectified voltage is slightly enhances. It has been noted that when the value $C_{2}$ is reduced to lower level ( $30 \mathrm{fF}$, maintaining $C_{1}=100 \mathrm{fF}$ ), the output voltage is also increases compared to case of equal capacitances. In the case of further increasing of capacitance (up to $0.5-1 \mathrm{pF}$ ), the output voltage level doesn't increases and in comparison with the suitable option for single-stage circuit $\left(C_{1}=100 \mathrm{fF}, C_{2}=30 \mathrm{fF}\right)$ even decreases. 
The defining of necessary numbers of rectifier stages was the next important step in the design of rectifier. For this, simulation of rectifier circuits with consistently increasing quantity of rectifying cells at constant storage capacitances was conducted, Figure 6b. According to the results of simulation, the rectified voltage reaches required $1.2 \mathrm{~V}$ at two stages $\left(V_{\mathrm{RF}} \approx 0.62 \mathrm{~V}\right)$. For a larger number of cascades, the amplitude of high-frequency sinusoidal signal, at which necessary voltage supply level can be obtained, is respectively lower. However one must take into account that circuit simulation has been conducted so far in the absence of some payload, therefore obtained values of voltage exceed the actual ones.

Based on the results of additional tests, it was found that values of storage capacitances $C_{1}=100 \mathrm{fF}$, $C_{2}=30 \mathrm{fF}$ are not suitable for 8-stage rectifier circuit. With a few trials, the acceptable capacitance values were taken equal to $C_{1}=200 \mathrm{fF}$ for odd numbers of capacitors and $C_{2}=150 \mathrm{fF}$ for even numbers. Further study of rectifier circuit was carried out assuming load resistance is $200 \mathrm{k} \Omega$ and number of stages is 8 .

Results of the transient simulation of 8 -stage rectifier at different temperatures $\left(-10{ }^{\circ} \mathrm{C}, 27{ }^{\circ} \mathrm{C}, 50{ }^{\circ} \mathrm{C}\right)$ are shown in Figure 6c. At lower temperature the rectified voltage is several tens of $\mathrm{mV}$ higher than the voltage obtained under normal conditions. At high temperatures the output voltage level decreases by approximately $0.01-0.02 \mathrm{~V}$ compared to normal conditions.

Figure $6 \mathrm{~d}$ shows comparison of operation of rectifier circuit using different types of MOS transistors. The curve of the output DC voltage in case of use of low-leakage transistors is denoted by a continuous line. The similar response for high-speed transistors is designated by a dashed line. Despite the difference in voltage levels is quite large $(0.15-0.2 \mathrm{~V})$, significant leakage currents prevent free using of high-speed devices.

In Figure 6e responses of the output voltages obtained for various design rules are shown. According to the study, when technological base $65 \mathrm{~nm}$ is used, the output voltage supply ( $0.7 \mathrm{~V}$ for this process) is attained at $V_{\mathrm{RF}} \approx 0.55 \mathrm{~V}$. The rectified voltage supply for process CMOS $45 \mathrm{~nm}(0.4 \mathrm{~V})$ can be obtained at less than $0.4 \mathrm{~V}$ at the input of the rectifier. Suchlike results demonstrate the broad prospects for further researches and developments of radiofrequency devices according to the advanced processes $45 \mathrm{~nm}$ and $65 \mathrm{~nm}$.

In order to increase the rectified DC voltage at the output of designed rectifier, the series of tests for enlargement the width of MOS transistors was conducted, Figure 6f. Actually, the ratio W/L was varied while the length of transistor remained unchanged. The ratio of the transistor width to its length in the using technology by default is $5(\mathrm{~W}=0.5 \mu \mathrm{m}, \mathrm{L}=0.1 \mu \mathrm{m})$. According to simulation results, each subsequent increasing of ratio W/L (up to 10, 20, 85) enhances the value of rectified voltage, which is natural, since current density in the transistor increases. However for ratio W/L $=10$ the output voltage is not sufficient for power supply. The ratio $\mathrm{W} / \mathrm{L}=85$ shows negligible enhancement of the output voltage compared to others variations and extremely high leakage currents $(\sim 700 \mathrm{nA})$. An acceptable ratio was $\mathrm{W} / \mathrm{L}=20(\mathrm{~W}=2 \mu \mathrm{m})$ at which the output voltage reaches the desired level of $1.2 \mathrm{~V}$ at an amplitude of the input signal less than $0.7 \mathrm{~V}$ (leakage current $<100 \mathrm{nA}$ at this ratio). The simulation results of the designed 8-stage rectifier for RFID tag operating at $2.45 \mathrm{GHz}$ are shown in Figure 7.

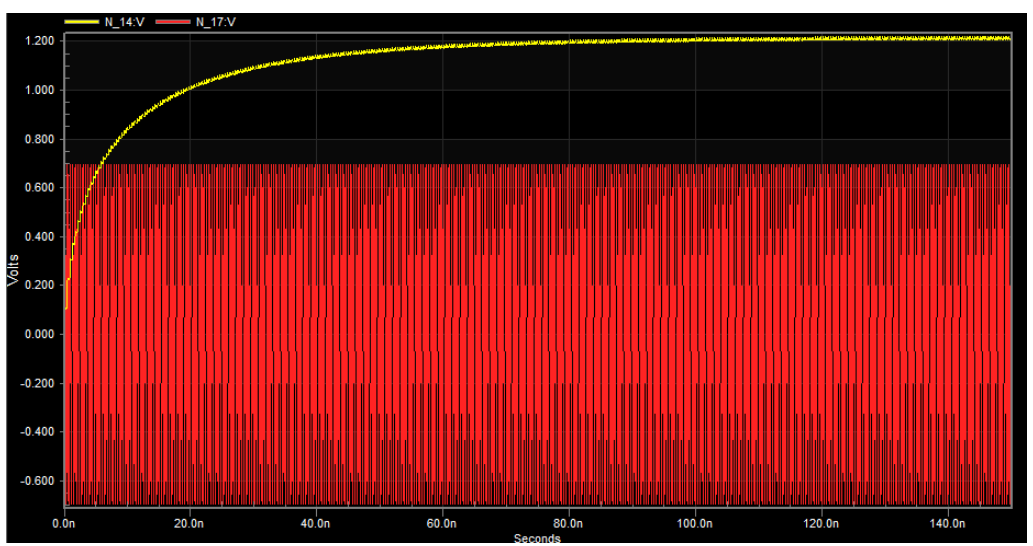

Figure7. The transient analysis results of the designed 8-stage rectifier with voltage multiplying at input signal amplitude $0.7 \mathrm{~V}$ and frequency $2.45 \mathrm{GHz}$

International Journal of Research Studies in Electrical and Electronics Engineering (IJRSEEE) Page | 16 
The simulation results of proposed reference-voltage source are shown in Figure 8. The rectified voltage arrives to reference-voltage source. The smoothed signal, formed here, with value of $0.42 \mathrm{~V}$ serves as the reference voltage in the voltage regulator circuit.

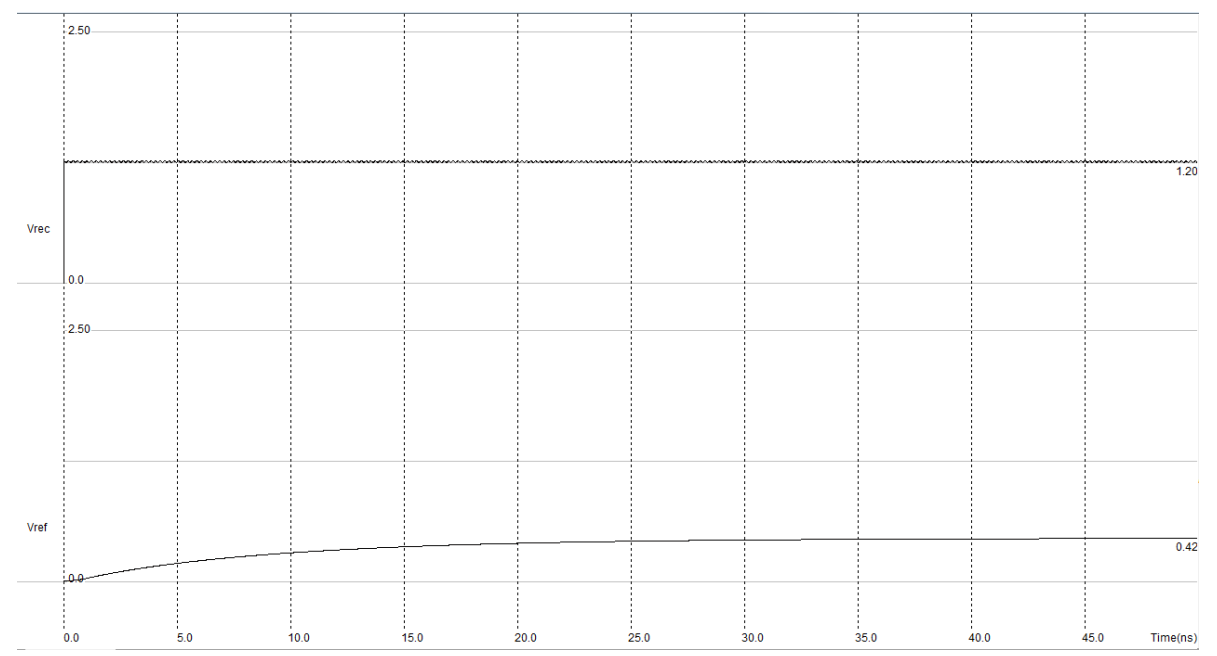

Figure8. The simulation results of voltage-reference source

\section{CONCLUSION}

In this paper the results of comprehensive simulation of the rectifier with charge pumping are presented. The device performance for various values of storage capacitance, number of stages, temperature, size of transistors and other parameters was studied. As a result the rectifier with charge pumping was developed. Diode-connected MOS transistors with enlarged channel width for rectifying the sinusoidal voltage and capacitors for charge accumulation and signal smoothing are used in 8stage circuit. The layout area of the device, designed for implementation on well-tried $90 \mathrm{~nm}$ CMOS technology, is $0.0153 \mathrm{~mm}^{2}$. The output voltage of the rectifier reaches required $1.2 \mathrm{~V}$ to provide power for the rest functional units of the tag at the input signal amplitude less than $0.7 \mathrm{~V}$ and frequency $2.45 \mathrm{GHz}$. In case of using $45 \mathrm{~nm}$ technology, it is possible to obtain required supply voltage $0.4 \mathrm{~V}$ at much lower input voltages $(0.35 \mathrm{~V})$ compared to $90 \mathrm{~nm}$ technology, while the operation frequency and the number of stages remain the same. In addition, the layout of referencevoltage to ensure operation of the voltage regulator is proposed.

\section{ACKNOWLEDGMENTS}

Author would like to thank his scientific adviser, Professor Boris G. Konoplev for his comprehensive assistance and discussion of the results of the work.

\section{REFERENCES}

[1] Finkenzeller K. RFID Handbook. Fundamentals and Applications in Contactless Smart Cards, Radio Frequency Identification and Near-Field Communication, 3rd ed. - Chichester, U.K.: Wiley, 2010, 462 pp.

[2] Hong Y., Chan C.F., Guo J., Ng Y.S., Shi W., Ho M., Leung L.K., Leung K.N., Choy C.S. and Pun K.P. Design and Challenges of Passive UHF RFID Tag in 90nm CMOS Technology. - EDSSC 2008, pp. 1-4.

[3] Sicard E., Bendhia S.D. Advanced CMOS Cell Design, 2nd ed. - McGraw-Hill, 2007, 364 pp.

[4] Pešić-Brđanin T., Dokić B.L. Strained Silicon Layer in CMOS Technology. - ELECTRONIS, 2014, Vol. 18, Issue 2, pp. 63-69.

[5] Liu D, Wang R., Yao K., Zou X., Guo L. Design and Implementation of a RF Powering Circuit for RFID Tags or Other Batteryless Embedded Devices. - Sensors (Basel), 2014, Vol. 14(8), pp. 14839 - 14857.

[6] Jamali B., Ranasinghe D.C., Cole P.H. Analysis of a UHF RFID CMOS rectifier structure and input impedance characteristics. - Proc. SPIE 6035, Microelectronics: Design, Technology, and Packaging II, 2006, 60350D.

[7] Dickson J.F. On-Chip High-Voltage Generation in MNOS Integrated Circuits Using an Improved Voltage Multiplier Technique. - IEEE Journal of Solid-State Circuits, 1976, Vol. 11, Issue 3, pp. 374-378.

[8] Dobkin D.M. The RF in RFID: Passive UHF RFID in Practice. - Oxford, U.K.: Elseveir, 2008, 493 pp.

[9] Sheu M.-L., Tiao Y.-S., Fan H.-Y., Huang J.-J. Implementation of a 2.45GHz Passive RFID Transponder Chip in 0.18 $\mu \mathrm{m}$ CMOS. - Journal of Information Science and Engineering, 2010, Vol. 26, pp. 597-610. 
[10] Yao W., Guangjun W., Wei M., Yanli H., Xueyong Z. Design of a passive UHF RFID tag for the ISO18000-6C protocol. - Journal of Semiconductors, 2011, Vol. 32, Issue 5, pp. 055009-1 - 055009-6.

[11] Che W., Yan N., Wang X., Min H. A Low Voltage Low Power RF-Analog Front-end Circuit for Passive UHF RFID Tag. - Shanghai, China: Fudan University, 2007, 12 pp.

[12] Yao Y., Wu J., Shi Y., Dai F.F. A Fully Integrated 900-MHz Passive RFID Transponder Front End With Novel Zero-Threshold RF-DC Rectifier. - IEEE Transactions on Industrial Electronics, 2009, Vol. 56, Issue 7, pp. 2317-2325.

[13] Fahsyar P.N.A., Soin N. A Proposed Low Power Voltage Multiplier for Passive UHF RFID Transponder. 2010 IEEE International Conference on Semiconductor Electronics, 2010, pp. 334-337.

[14] Sicard E. Microwind \& DSCH v3.5 - Lite User's Manual. - Toulouse, France: INSA Toulouse, 2009,130 pp.

\section{AUTHOR'S BIOGRAPHY}

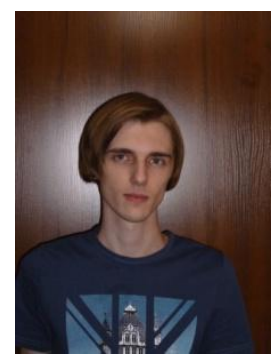

Alexander S. Sinyukin, received the BSc degree in Design engineering and technology of electronic devices at Southern Federal University, Taganrog, Russia, in 2015 and the MSc degree at the same university and the same area of study in 2017. Currently, he studies and works at Southern Federal University. His research interests include radiofrequency energy-efficient Microsystems with wireless power.

Citation: Alexander S. Sinyukin (2017). Design of Power Supply Unit for Passive UHF RFID Tag, International Journal of Research Studies in Electrical and Electronics Engineering (IJRSEEE), 3(2), pp. 1118, DOI: http://dx.doi.org/10. 20431/2454-9436.0302002.

Copyright: (c) 2017 Alexander S. Sinyukin. This is an open-access article distributed under the terms of the Creative Commons Attribution License, which permits unrestricted use, distribution, and reproduction in any medium, provided the original author and source are credited 